\title{
Comparative evaluation of microleakage of nano-filled resin-modified glass ionomer: An in vitro study
}

\author{
Nesrin Eronat ${ }^{1}$, Emir Yilmaz ${ }^{1}$, Nazan Kara ${ }^{1}$, Asli Topaloglu Ak ${ }^{1}$
}

Correspondence: Dr. Asli Topaloglu Ak Email: aslitopaloglu@yahoo.com
'Department of Pediatric Dentistry, Faculty of Dental, Ege University, Izmir, Turkiye

\section{ABSTRACT}

Objective: This in vitro study evaluated the microleakage of a nano-filled resin-modified glass ionomer and a high viscosity glass-ionomer restorations in class V cavities. Materials and Methods: Thirty-two class V cavities prepared on the buccal and lingual surfaces of 16 sound, third molar teeth were randomly assigned into two groups and restored by one of the glass ionomer material; Group A: A high viscosity (Ketac Molar, 3M ESPE) Group B: A nano-filled resin-modified (Ketac N100, 3M ESPE) glass ionomer. One clinician prepared all the cavities. The materials were used according to the manufacturers' recommendations. The restored teeth were then stored in distilled water at $37^{\circ} \mathrm{C}$ for $24 \mathrm{~h}$, thermocycled at $5-55^{\circ} \mathrm{C}$ for 1000 cycles. The specimens were immersed in aqueous solution of Indian ink dye for $48 \mathrm{~h}$ at room temperature. They were embedded in resin polyester and sectioned longitudinally in a buccolingual direction. Microleakage was assessed according to the depth of dye penetration along the restoration. The extent of dye penetration at the occlusal and gingival margins was assessed using a stereo microscope. Randomly selected samples from each group were prepared for scanning electron microscope evaluation. The data were statistically analyzed with Friedman and Wilcoxon signed ranks tests. Results: There were statistically significant differences between the microleakage scores of the two groups for both occlusal and gingival scores $(P=0.001)$. Occlusal and gingival scores for high viscosity glass ionomer $(P=0.024)$ and nanoionomer $(P=0.021)$ using Wilcoxon signed ranks tests showed statistically significant differences. High viscosity glass ionomer showed significantly less microleakage compared to the nano-filled resin-modified glass-ionomer (RMGIs) at occlusal margin $(P=0.001)$. No significant differences were found between the groups at gingival margin $(P=0.0317)$. Conclusion: Within the limitations of this in vitro study, nano-filled RMGIs restorations did not perform better than high viscosity glass ionomer in class $\mathrm{V}$ cavities in terms of microleakage assessment.

Key words: High viscosity glass ionomer, microleakage, nanoionomer

\section{INTRODUCTION}

Glass ionomer cements (GIC) are commonly used in restorative and pediatric dentistry for their long-term fluoride release and ease of use. They are biocompatible with pulpal tissue as well. Glass ionomers are also accepted as the best dentin replacement materials available for the clinician. However, disadvantages related to glass ionomers; such as lack of strength, prolonged setting time, moisture sensitivity, dehydration, and poor esthetics are reported..$^{[1-3]}$ Due to these disadvantages of the conventional GIC, hybrid versions of the material were introduced. Among these, resin-modified glass-ionomers (RMGIs) that can be photocured is said to have better physical characteristics. ${ }^{[4]}$ Besides the advantages of glass ionomers, their ease of placement, early resistance to moisture contamination, and setting in the command created great interest both in pedodontics and orthodontics. Developments in GIC resulted in improved esthetics in comparison to conventional glass ionomers. High viscosity glass ionomers are also a good

\footnotetext{
How to cite this article: Eronat N, Yilmaz E, Kara N, Ak AT. Comparative evaluation of microleakage of nano-filled resin-modified glass ionomer: An in vitro study. Eur J Dent 2014;8:450-5.

Copyright $\odot 2014$ Dental Investigations Society. DOI: $10.4103 / 1305-7456.143615$
} 
alternative for clinical application since it is reported that their physical properties are improved..$^{[5-7]}$

With the application of nanotechnology in this field, a novel RMGI has been introduced in the market which is classified as nano-filled resin-modified glassionomer (nano-ionomer).$^{[8]}$ Ketac N100 is a new paste/ paste nanoinomer with a filler composition of $69 \%$. The glass component of Ketac N100 consists of nanofiller (5-25 nm) and nanofiller clusters $(1-1.6 \mu \mathrm{m})$. It has an easy mixing system which needs the use of a priming step but separate conditioning. Light activation is required for polymerization. It is claimed to have practical use both in primary and permanent dentition. Although mechanical properties are said to be improved, clinical and laboratory studies are lacking. Thus, the adhesiveness of the material is not clear yet. ${ }^{[6,9]}$

Microleakage has been reported as the main issue with restorations and influenced the restoration longevity. It is defined as the leakage of microorganisms and toxins between the restoration and walls of cavity preparation. In a clinical situation, this may lead to marginal breakdown, postoperative hypersensitivity, recurrent caries, which are major problems in restorative dentistry. ${ }^{[9]}$ In laboratory studies, microleakage evaluation is commonly used for sealing the effectiveness of restorative materials. ${ }^{[10]}$

Thus, the aim of this in vitro study is to evaluate the microleakage of nano-filled resin-modified glass ionomer in comparison to high viscosity glass-ionomer in class $\mathrm{V}$ restorations.

\section{MATERIALS AND METHODS}

Sixteen freshly extracted noncarious human third molars which were stored in distilled water containing thymol crystals for up to 1 month at $4^{\circ} \mathrm{C}$ were test specimens. After surface debridement, they were examined for defects in enamel and dentin using magnifying glasses. Totally, 32 Class $\mathrm{V}$ cavities were prepared on the buccal and the lingual/ palatinal surfaces of molars underwater cooling with high-speed hand piece using round and cylindrical diamond burs. The bur was replaced every four preparations. Preparation of the cavities was standardized using a template. Preparations measured $4 \mathrm{~mm}$ long, $3 \mathrm{~mm}$ wide, and $2 \mathrm{~mm}$ deep with the occlusal margin in enamel and the gingival margin in dentin/cementum. The depth of the cavity was measured by a pre-marked periodontal probe. The cavities were rinsed and dried with a water/air spray. One clinician prepared all the cavities. Following cavity preparation, the restorative materials were randomly assigned to an equal number of buccal and lingual cavities and placed according to the manufacturers' instructions. Each cavity was restored by one of the glass ionomers: Group A; a high-viscosity conventional GIC (Ketac Molar, 3M-ESPE); and Group B; a nano-filled resin-modified GIC-Ketac Nano (Ketac N100, 3M-ESPE).

The composition and manufacturers of the materials used in this study are presented in Table 1.

In group $\mathrm{A}$, the liquid of Ketac Molar as the cavity conditioner was applied to the enamel and dentin surfaces with a brush for $10 \mathrm{~s}$. Subsequently, it was rinsed using a water spray, air-dried for $5 \mathrm{~s}$ and high viscosity GIC was placed to the cavity. Excess material was removed, and the restoration was coated with petroleum jelly.

In group B, nanoionomer primer was applied to the cavity for $15 \mathrm{~s}$ and thinned with a stream of dry air for $10 \mathrm{~s}$. It was light-cured for $10 \mathrm{~s}$ using a visible light curing device at $500 \mathrm{~mW} / \mathrm{cm}^{2}$ (Elipar FreeLight 2, 3M-ESPE, Seefeld, Germany). An equal amount of two pastes was dispensed, and mixed with a plastic spatula for $20 \mathrm{~s}$ and applied to the cavity and light-cured for $20 \mathrm{~s}$.

The restorations were finished with fine-grit finishing diamond burs and polished with the disc system (Sof-Lex). The restored teeth were stored in distilled water at $37^{\circ} \mathrm{C}$ for $24 \mathrm{~h}$. The specimens were then thermocycled at $5^{\circ} \mathrm{C}$ and $55^{\circ} \mathrm{C}$ for 1000 cycles with a dwell time of $30 \mathrm{~s}$ at each temperature and $10 \mathrm{~s}$ transfer time between baths.

\begin{tabular}{|c|c|c|}
\hline Materials & Manufacturer & Composition \\
\hline $\begin{array}{l}\text { Ketac N100 } \\
\text { (light-curing } \\
\text { nano-ionomer } \\
\text { restorative) }\end{array}$ & $\begin{array}{l}\text { 3M ESPE, } \\
\text { Seefeld, } \\
\text { Germany }\end{array}$ & $\begin{array}{l}\text { Deionized water, blend, } \\
\text { including HEMA, } \\
\text { a methacrylate-modified } \\
\text { polyalkenoic acid } \\
\text { Filler content; methacrylate } \\
\text { functional-fluoroaluminosilicate } \\
\text { glass and nanomeres } \\
\text { and nanoclusters }\end{array}$ \\
\hline $\begin{array}{l}\text { Ketac molar } \\
\text { (high viscosity GI) }\end{array}$ & $\begin{array}{l}\text { 3M ESPE, } \\
\text { Seefeld, } \\
\text { Germany }\end{array}$ & $\begin{array}{l}\text { Powder: Al-Ca-La flourosilicate } \\
\text { glass } 5 \% \text { copolymer acid } \\
\text { (acrylic and maleic acid) } \\
\text { Liquid: Polyalkenoic acid, } \\
\text { tartaric acid, water }\end{array}$ \\
\hline
\end{tabular}




\section{Microleakage assessment}

After thermocycling, the apices of the roots were sealed with modeling wax and the specimens were coated with two layers of nail polish, leaving a $1 \mathrm{~mm}$ window around the cavity margins. The teeth were immersed in an aqueous solution of Indian ink for $48 \mathrm{~h}$ at room temperature, then removed from the dye, rinsed in tap water for $30 \mathrm{~s}$ and dried. Subsequently, teeth were embedded in polyester and sectioned longitudinally in a buccolingual direction through the center of both cavities using a low-speed diamond saw (Isomet, Buehler, Ltd, Lake Bluff, IL, USA).

The dye penetration depth along the occlusal and gingival margins toward the axial wall, were evaluated. Dye penetration scores were analyzed by two calibrated and blinded evaluaters (Nesrin Eronat, Asli TopalogluAk). The scoring criteria used for the study are shown in Figures 1 and 2. The section with the greater leakage score was considered for statistical analysis.

\section{Scanning electron microscope analysis}

Four randomly selected samples from each group were prepared for scanning electron microscope (SEM) evaluation. The specimens were dehydrated and mounted on aluminum stubs and gold-sputter coated. The SEM (JSM-5200 Electron Probe Micro-analyzer SEM, JOEL, Ltd, Tokyo, Japan) was used to assess

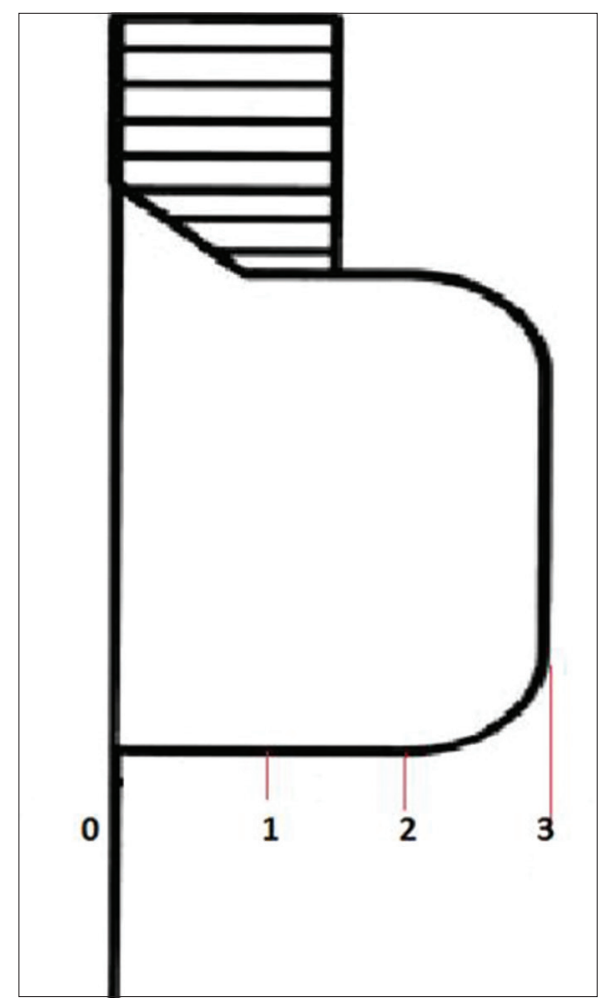

Figure 1: Schematic cross-section of restoration illustrates scoring system marginal adaptation of the two tested glass ionomer materials to tooth structure at $\times 50$ magnification.

\section{Statistical analysis}

The data were analyzed using statistical package for social sciences (Version 19.0, SPSS Inc. Chicago, IL, USA). Friedman test was used to compare the microleakage scores of the materials for both occlusal and gingival margins. Ranking for the two materials was compared using the Wilcoxon Signed Ranks test. The statistically significance level was set at $P<0.05$.

\section{RESULTS}

\section{Microleakage}

Measurement of agreement was found to be outstanding (0.94) between the two evaluaters. Dye penetration scores obtained for each group in the occlusal and gingival margins are presented in Table 2. A statistically significant difference was found between the leakage scores among the two materials tested (Group A and Group B) and both at the occlusal and gingival margins $(P<0.001)$. Further analysis by Wilcoxon test was undertaken to compare leakage scores at the occlusal and gingival margins of each material, which revealed statistically significant difference at the occlusal margins between the two materials $(P=0.001)$. There was no significant difference between the leakage scores of two materials at the gingival margins $(P=0.317)$. Statistically significant difference was found between Ketac N100 and Ketac Molar when leakage scores of occlusal margins are compared to gingival scores in each material $(P=0.021$ and $P=0.024$, respectively) [Table 2].

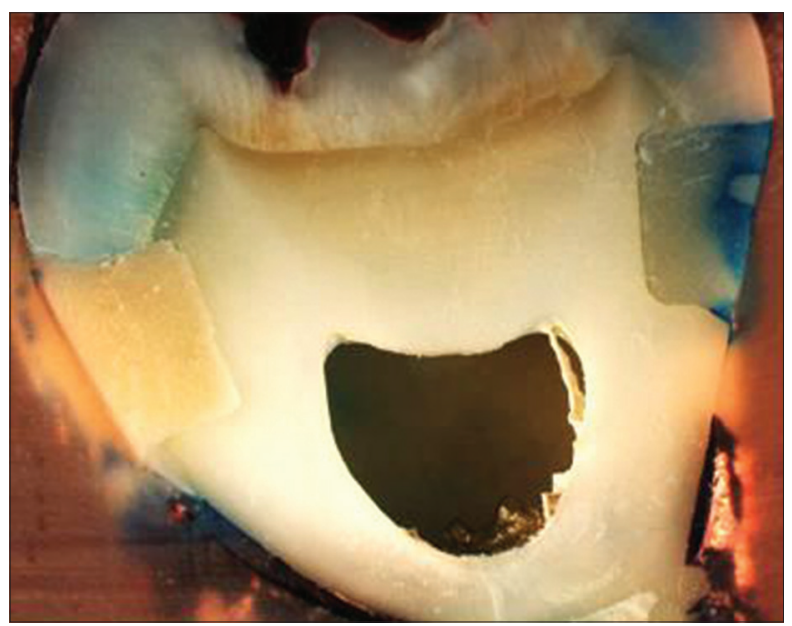

Figure 2: A sample in which nano-filled resin-modified glass ionomer (at right side; scored as 2 occlusally and 1 gingivally) and high viscosity glass ionomer cement (at left side; scored as 0 for both occlusally and gingivally) was applied to the class $\mathrm{V}$ cavities in the same tooth 


\section{Scanning electron microscope}

The occlusal and gingival margins of both high viscosity glass ionomer and nano-ionomer cement restorations were examined, and the presence of gaps was noted. Gaps between the tooth structure and GIC were similar for both materials [Figures 3 and 4]. Bond interface of Ketac N100 specimens showed an indistinct interface between the margin of the tooth structure and the restoration. Nano-filled resin-modified glass ionomer showed similar appearance with dentin, and it was difficult to distinguish between the material and tooth structure.

\section{DISCUSSION}

In the present in vitro study, the microleakage of nano-filled resin-modified glass ionomer restorations placed in class $\mathrm{V}$ cavities was evaluated using a dye penetration test and compared with a high viscosity glass ionomer. Class $\mathrm{V}$ preparations were chosen to study the tested materials in a high $\mathrm{C}$-factor design. ${ }^{\left[{ }^{[9]}\right.}$ Thermocycling has been used to simulate oral conditions which is widely used in dental research. The number of cycles used in this study (1000 cycles) is in accordance with the number of cycles mentioned in previous studies. ${ }^{[11]}$

\begin{tabular}{|c|c|c|c|c|c|c|c|c|c|}
\hline \multirow[t]{2}{*}{ Groups } & \multicolumn{4}{|c|}{ Occlusal } & \multicolumn{4}{|c|}{ Gingival } & \multirow[t]{2}{*}{$P$} \\
\hline & 0 & 1 & 2 & 3 & 0 & 1 & 2 & 3 & \\
\hline $\begin{array}{l}\text { Ketac molar } \\
(\text { Group A) } n=16\end{array}$ & 7 & 5 & 3 & 1 & 3 & 1 & 9 & 3 & 0.024 \\
\hline $\begin{array}{l}\text { Ketac N100 } \\
\text { (Group B) } n=16\end{array}$ & 0 & 3 & 5 & 8 & 0 & 10 & 4 & 2 & 0.021 \\
\hline$P$ & 0.001 & & & & $0.317^{*}$ & & & & \\
\hline
\end{tabular}

*Statistically insignificant. Gl: Glass ionomer
The longevity of the restoration is largely determined by marginal sealing of the cavity. ${ }^{[12]}$ Thus, the ability of restoration to minimize the extension of microleakage at the tooth/restoration interface is important in predicting its clinical success. A variety of methods was used to evaluate the extent of microleakage and the marginal integrity of restorations. The use of dye diffusion is one of the most commonly used methods. ${ }^{[13]}$ Studies on marginal sealing by measurement of microleakage may be carried out using different techniques. These are namely use of different types of dyes, chemical markers, radioactive isotopes, air pressure, bacteria, and electrochemical method. ${ }^{[14]}$ The most commonly methods were those with stained solutions-methylene blue, aniline blue, fluorescein, eosin, erythrosine, and Indian ink. ${ }^{[10,15]}$ Advantages of using stained solutions include precision in assessment of marginal sealing, possibility of direct reading of the diffused marker under the microscope, and simplicity of application. Disadvantage of the method is reflected in considerably smaller diameter of the marker particle in comparison to the bacterial toxin molecule and bacteria themselves. In this study, Indian ink ( $\mathrm{pH}$ 7.5) was used for dye penetration due to its adequate visualization after clearing of the specimens. Particle sizes of the ink suspension are suitable for detecting microleakage occurrence since they can easily penetrate through the cracks. ${ }^{[16]}$

In the present study, none of the materials evaluated completely eliminated microleakage at the occlusal or gingival margins of the restoration. Microleakage scores of the nano-filled resin-modified glass ionomer (nanoionomer) were not found superior to high viscosity glass ionomer cement (HVGIC) either. Comparison of the dye penetration scores of the two glass ionomer materials tested revealed significant
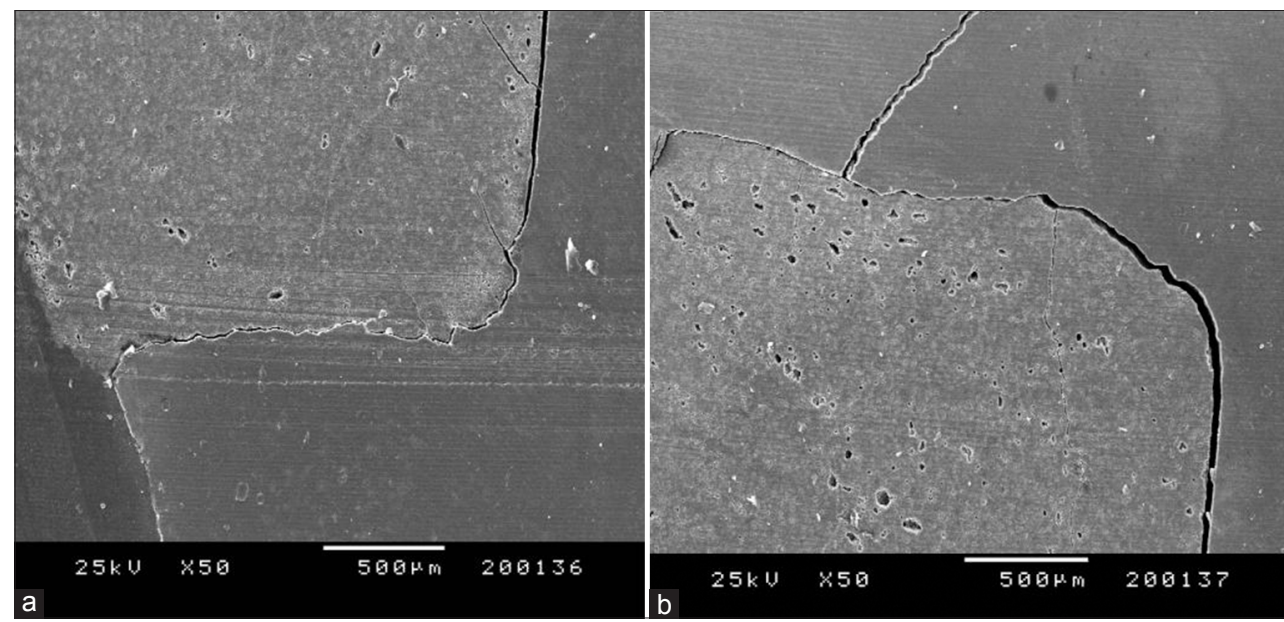

Figure 3: Scanning electron microscope micrograph of (a) gingival and (b) occlusal margins of Ketac Molar ( $\times 50)$ 


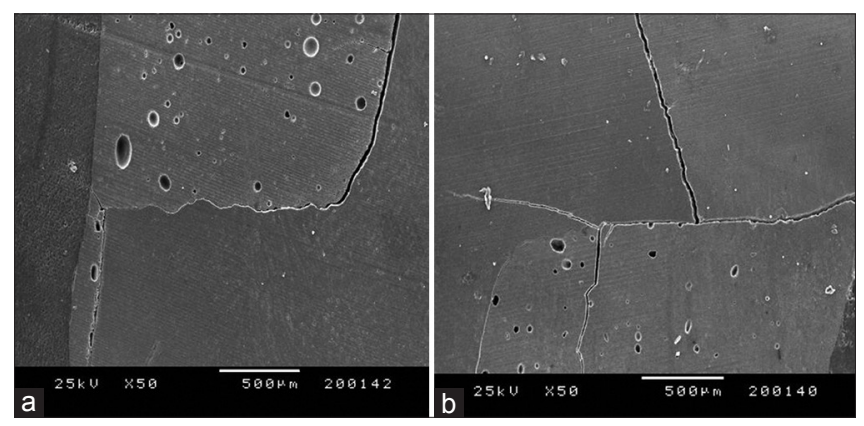

Figure 4: Scanning electron microscope micrograph of (a) gingival and (b) occlusal margins of Ketac N100 (×50)

difference in the leakage at the occlusal margin and the marginal sealing of high viscosity glass ionomer was better, while nano-ionomer demonstrated less or similar microleakage than the high viscosity glassionomer cement at the gingival margin [Table 2].

Our results for nano-filled resin-modified glass ionomer showing higher microleakage scores at the occlusal margin may be explained by the resin content increasing the polymerization shrinkage. This finding is in agreement with some studies that mention GIC that undergo minimal setting shrinkage and approximately one half that of resins. ${ }^{[17-19]}$ It is reported that marginal seal achieved by GICs was comparable or even superior to conventional composite resins. Furthermore, the restoration of a tooth with a class $\mathrm{V}$ cavity could be indifferently performed using either a flowable composite or glassionomer cement. ${ }^{[12,18]}$ Thus, since the resin component is responsible for the polymerization shrinkage of light-cured glass ionomers, it may produce polymerization shrinkage which could adversely affect marginal adaptation. ${ }^{[17,19]}$ The dentin treatment procedures performed when placing the materials may also affect the marginal adaptation. The difference observed in the microleakage between the enamel (occlusal) and dentin (gingival) margins may be due to a difference in the quality of the bond between the materials and enamel and dentin structures. It is also reported that enamel (occlusal) margins of permanent teeth restored with GICs show less microleakage than dentin (gingival) margins. ${ }^{[12]}$ This is in accordance with our findings; in group A, more samples showed lower leakage scores than samples in group B at the occlusal margin.

It is mentioned that the bonding mechanisms of resin modified glass ionomers may not be so strong, and contraction of the material may exist as the material matures. ${ }^{[20]}$ Glass ionomers may produce more adequate marginal sealing since chemical interactions take place with polyalkenoic acids and hydroxyapatite. ${ }^{[20]}$ HVGIC's strong chelation reaction with calcium on the tooth surface might have made its effect comparable to nano-filled glass ionomers.

Contrary to our findings, some investigations showed that the nanoionomer demonstrated less microleakage compared to conventional glass-ionomer cement. ${ }^{[21-23]}$ In a study, microleakage of composite, nanoionomer, and conventional glass-ionomer cement was investigated in endodontically treated premolar teeth used as a coronal barrier and no statistically significant difference was found between the materials. ${ }^{[23]}$ In the same study, it is also stated that nanoionomer cement when used as intraorifice barrier under composite showed less microleakage. ${ }^{[23]}$ However, it must be noted that different study protocols such as teeth storage, number of cycles in thermocycling, and different periods in different dye solutions may affect the results of microleakage studies. ${ }^{[21-26]}$

In the nano-filled type of glass ionomer, lower polymerization shrinkage may be expected since higher filler loading is found. ${ }^{[21]}$ On the other hand, Coutinho et al. ${ }^{[6]}$ reported that nanoionomers exhibited a superficial dentin and enamel interaction. Thus, micro mechanical interlocking was found inadequate. Abd El Halim et al. ${ }^{[21]}$ compared the microleakage of three glass ionomers in vitro and found that leakage occurs with all types of glass ionomer with an increase in immersion time. They reported that nano-filled RMGI (Ketac N100) showed the lowest microleakage scores followed by the other resin-modified glass ionomer (Vitremer) and resin-modified synthetic glass polyalkenoate (Photac Fil Quick) after immersion in synthetic saliva for 60 days. This finding is not in accordance with our findings since teeth storage media and the experimental model used were different. They also reported that microleakage scores were higher at the gingival margin than the occlusal margin for all the materials tested. This is explained by the fact that cavity preparations with enamel margins result in stronger bonds since the inorganic structure is higher in enamel than dentin.

In our electron microscope images, bond interface of Ketac N100 specimens showed an indistinct interface between the margin of the tooth structure and the restoration. Nanoionomer also showed similar appearance with dentin, and it was difficult to distinguish between the material and tooth structure. This may be due to its nanostructure and micromechanical bonding at the interface between 
the material and tooth structure. This finding was inconsistent with the dye penetration scores achieved. Nevertheless, the similarity of gaps and feature in both restorative materials was noteworthy.

The results of the present study showed that nano-filled RMGI is not more advantageous than high viscosity glass ionomers from the perspective of effective marginal sealing in class $V$ cavities. Further studies and long-term clinical data are required to confirm our findings.

\section{CONCLUSION}

Within the limitations of this in vitro study, nano-filled resin-modified glassionomer restorations did not show less microleakage than high viscosity glass ionomer material tested in class $\mathrm{V}$ cavities.

\section{REFERENCES}

1. Leinfelder KF. Glass ionomers: Current clinical developments. J Am Dent Assoc 1993;124:62-4.

2. Croll TP. Glass ionomers and esthetic dentistry: What the new properties mean to dentistry. J Am Dent Assoc 1992;123:51-4.

3. McLean JW. The clinical use of glass-ionomer cements - future and current developments. Clin Mater 1991;7:283-8.

4. Croll TP. Nanofilled resin-modified glass ionomer restorative cement. Contemp Esthet 2007;11:14-7.

5. Markovic DL, Petrovic BB, Peric TO. Fluoride content and recharge ability of five glassionomer dental materials. BMC Oral Health 2008;8:21.

6. Coutinho E, Cardoso MV, De Munck J, Neves AA, Van Landuyt KL, Poitevin A, et al. Bonding effectiveness and interfacial characterization of a nano-filled resin-modified glass-ionomer. Dent Mater 2009;25:1347-57.

7. Croll TP, Nicholson JW. Glass ionomer cements in pediatric dentistry: Review of the literature. Pediatr Dent 2002;24:423-9.

8. Moszner N, Salz U. New developments of polymeric dental composites. Program Polym Sci 2001;26:535-76.

9. El-Ashiry EA, Bakry NS, Farsi N, Farsi D. Microleakage evaluation of two different nano-restorative materials in primary molars: In vitro study. Life Sci J 2012;9:2292-300.

10. Raskin A, D'Hoore W, Gonthier S, Degrange M, Déjou J. Reliability of in vitro microleakage tests: A literature review. J Adhes Dent 2001;3:295-308.

11. Gupta KV, Verma P, Trivedi A. Evaluation of microleakage of various restorative materials: An in vitro study. J Life Sci 2011;3:29-33.

12. Wadenya R, Mante FK. An in vitro comparison of marginal microleakage of alternative restorative treatment and conventional glass ionomer restorations in extracted permanent molars. Pediatr Dent 2007;29:303-7.

13. Van Meerbeek B, De Munck J, Yoshida Y, Inoue S, Vargas M, Vijay P, et al. Buonocore memorial lecture. Adhesion to enamel and dentin: Current status and future challenges. Oper Dent 2003;28:215-35.

14. Heintze S, Forjanic M, Cavalleri A. Microleakage of Class II restorations with different tracers: Comparison with SEM quantitative analysis. J Adhes Dent 2008;10:259-67.

15. Youssef MN, Youssef FA, Souza-Zaroni WC, Turbino ML, Vieira MM. Effect of enamel preparation method on in vitro marginal microleakage of a flowable composite used as pit and fissure sealant. Int J Paediatr Dent 2006;16:342-7.

16. Youngson CC, Jones JC, Manogue M, Smith IS. In vitro dentinal penetration by tracers used in microleakage studies. Int Endod J 1998;31:90-9.

17. Toledano M, Osorio E, Osorio R, García-Godoy F. Microleakage of Class V resin-modified glass ionomer and compomer restorations. J Prosthet Dent 1999;81:610-5.

18. Magni E, Zhang L, Hickel R, Bossù M, Polimeni A, Ferrari M. SEM and microleakage evaluation of the marginal integrity of two types of class $\mathrm{V}$ restorations with or without the use of a light-curable coating material and of polishing. J Dent 2008;36:885-91.

19. Brackett WW, Gunnin TD, Gilpatrick RO, Browning WD. Microleakage of Class V compomer and light-cured glass ionomer restorations. J Prosthet Dent 1998;79:261-3.

20. Mitra SB, Lee CY, Bui HT, Tantbirojn D, Rusin RP. Long-term adhesion and mechanism of bonding of a paste-liquid resin-modified glass-ionomer. Dent Mater 2009;25:459-66.

21. Abd El Halim S, Zaki D. Comparative evaluation of microleakage among three different glass ionomer types. Oper Dent 2011;36:36-42.

22. Upadhyay S, Rao A. Nanoionomer: Evaluation of microleakage. J Indian Soc Pedod Prev Dent 2011;29:20-4.

23. Deepali S, Hedge MN. Coronal microleakage of four restorative materials used in endodontically treated teeth as a coronal barrier-an in vitro study. Endodotology, 27-35.

24. Antonson SA, Yazici AR, Okte Z, Villalta P, Antonson DE, Hardigan PC. Effect of resealing on microleakage of resin composite restorations in relationship to margin design and composite type. Eur J Dent 2012;6:389-95.

25. Erdilek D, Dörter C, Koray F, Kunzelmann KH, Efes BG, Gomec Y. Effect of Thermo-mechanical Load Cycling on Microleakage in Class II Ormocer Restorations. Eur J Dent 2009;3:200-5.

26. Idriss S, Abduljabbar T, Habib C, Omar R. Factors associated with microleakage in Class II resin composite restorations. Oper Dent 2007;32:60-6.

\begin{tabular}{|l|l|}
\hline \multicolumn{2}{|c|}{ Access this article online } \\
\hline Quick Response Code: & Website: \\
\hline & www.eurjdent.com \\
\hline
\end{tabular}

